\title{
Utilização de Três Fontes de Nitrogênio Associadas à Palma Forrageira (Opuntia ficus-indica, Mill.) Cv. Gigante na Suplementação de Vacas Leiteiras Mantidas em Pasto Diferido ${ }^{1}$
}

\author{
Samuel Salgado Cavalcanti de Albuquerque ${ }^{2}$, Mário de Andrade Lira ${ }^{3}$, Mércia Virgínia Ferreira \\ dos Santos ${ }^{4}$, José Carlos Batista Dubeux Júnior ${ }^{5}$, José Nilson de Melo ${ }^{6}$, Iderval Farias ${ }^{7}$
}

RESUMO - O fornecimento da palma forrageira como único alimento não atende as necessidades nutricionais do rebanho, notadamente em proteína e fibra. Nesta pesquisa avaliaram-se fontes de suplementação protéica sobre o desempenho de vacas leiteiras alimentadas com palma e pasto diferido, durante a estação seca, bem como a composição botânica da pastagem. Testaram-se três tratamentos: $\mathrm{T}_{1}=$ pasto diferido $(\mathrm{PD})+$ palma + cama de aviário; $\mathrm{T}_{2}=\mathrm{PD}+$ palma + farelo de soja e $\mathrm{T}_{3}=\mathrm{PD}+$ palma + uréia/sulfato de amônio, em um delineamento de blocos casualizados. Utilizaram-se 12 vacas mestiças 5/8 Holando-Zebu, com produção média de leite de $5,6 \mathrm{~kg} / \mathrm{dia} /$ vaca e peso vivo (PV) médio de $452 \mathrm{~kg}$. O experimento teve duração de 121 dias, sendo 21 dias de período de adaptação. Os resultados para produção de leite in natura $(3,38,5,33$ e $3,38 \mathrm{~kg} / \mathrm{vaca} /$ dia $)$, produção de leite corrigido para $4 \%$ de gordura $(3,15$, 4,98 e 3,11 kg/vaca/dia), variação de peso vivo (-351, 77 e -401 g/vaca/dia) e consumo in natura de palma (26,3, 37,8 e 26,3 kg/vaca/dia), para $\mathrm{T}_{1}, \mathrm{~T}_{2} \mathrm{e} \mathrm{T}_{3}$, respectivamente, demonstraram a superioridade do farelo de soja como fonte protéica, em relação aos demais tratamentos. No pasto diferido foram identificados 18 famílias, 32 gêneros e 36 espécies. O capim-milhã (Brachiaria plantaginea (Link) Hitch) foi o componente de maior participação na composição botânica da pastagem (28,72\%).

Palavras-chave: composição botânica, produção de leite, semi-árido, suplemento proteíco.

\section{Utilization of Three Nitrogen Sources Associated to Cactus Forage (Opuntia ficus-indica, Mill.) cv. Gigante in Dairy Cows Supplementation Grazing at Differed Pasture}

\begin{abstract}
The cactus forage only feed for herd not attend nutritional requeriments, because it is poor in protein and fiber. Protein supplementation sources upon the dairy cows performance fed with cactus forage, grazing at differed pasture, and botanic composition of pastre, were evaluated. Three treatments were tested: $\mathrm{T} 1=$ differed pasture $(\mathrm{DP})+$ cactus forage $(\mathrm{CF})+$ broiler litter; $\mathrm{T} 2=\mathrm{DP}+\mathrm{CF}$ + soybean meal; $\mathrm{T} 3=\mathrm{DP}+\mathrm{CF}+$ urea/ammonium sulphate mixture. It was used a randomized block design. The experimental animals were twelve $5 / 8$ holstein/Zebu multiparous cows, with an average of seven years of age, milk yield of $5.6 \mathrm{~kg} / \mathrm{cow} / \mathrm{day}$, and mean of $452 \mathrm{~kg}$ of live weight. The experimental period was 121 days and the first 21 days was used as an adaptation period. The results to fresh milk yield (3.38, 5.33 and $3.38 \mathrm{~kg} / \mathrm{cow} /$ day), $4 \%$ fat adjusted milk yield (3.15, 4.98 and $3.11 \mathrm{~kg} /$ cow/day), daily live weight gain (-351, $77 \mathrm{and}-401 \mathrm{~g} / \mathrm{cow} /$ day) and fresh cactus forage intake (26.3, 37.8 and $26.3 \mathrm{~kg} / \mathrm{cow} /$ day) considering T1, T2 and T3, respectively, showed the best performance to cows fed with soybean meal as supplemental protein source. It was identified 18 families, 32 genus and 36 species in the pasture. The "capim-milhã" (Brachiaria plantaginea (Link) Hitch.) was the main component in the botanical composition (28.72\%).
\end{abstract}

Key Words: protein supplement, botanical composition, milk yield, semi-arid region

\section{Introdução}

A bovinocultura leiteira desenvolvida no Agreste Pernambucano representa $60 \%$ do leite produzido no Estado, sendo uma atividade de grande importância econômica e social (Pimentel, 1998; França et al., 1999).
Obter fontes alimentares alternativas para bovinos que possam minimizar os resultados do período de seca tem sido uma busca constante. Dentre as alternativas, a palma forrageira tem se constituído em fonte potencial de água e forragem para os animais nesta época do ano. Isto reduz os efeitos negativos da seca sobre o desempenho animal, a

\footnotetext{
${ }^{1}$ Parte da dissertação do primeiro autor apresentada ao Programa de Pós-Graduação em Zootecnia da UFRPE.

2 Professor da Escola Agrotécnica Federal de Belo Jardim - PE. Mestre pelo PPGZ da UFRPE.

3 Pesquisador do IPA e bolsista do CNPq. E.mail: mlira@ipa.br

4 Professor da UFRPE. Rua Manoel de Medeiros, s/n, Dois Imãos, Recife-PE, CEP: 52171-900. E.mail: rmsantos@elogica.com.br

5 Professor da UFRPE e bolsista do CNPq. E.mail: dubeux@ufl.edu

${ }^{6}$ Pesquisador do IPA, in memorian.

${ }^{7}$ Pesquisador do IPA, E.mail: iderval@ipa.br
} 
exemplo do que ocorreu recentemente quando a região presenciou dois ciclos intensos de seca, 1992-1993 e 1998-1999. Vale ressaltar que a palma é uma forragem que os animais consomem com facilidade, podendo o consumo individual chegar até $104 \mathrm{~kg} / \mathrm{dia} /$ vaca de material in natura (Santos et al., 1998).

Entretanto, apenas com o fornecimento dessa cactácea não é possível atender às necessidades nutricionais do rebanho, considerando, notadamente, sua limitação protéica e de fibra. Dessa forma, para adequar a dieta, torna-se necessário que o produtor recorra a outros meios disponíveis de suplementação alimentar, através do uso de volumosos e de fontes de proteína.

O pasto nativo é uma alternativa de suplementação volumosa. Segundo Maraschin (1986), o diferimento é uma prática excelente e, muitas vezes, evita a perda de animais. Porém, Neiva \& Santos (1998) chamam a atenção para o aspecto de que esta prática pode resultar em perdas da quantidade e qualidade da forragem reservada. Por outro lado, o diferimento influencia a composição botânica da pastagem, conforme observado por Fernandes et al. (1983).

A suplementação alimentar do rebanho é uma técnica conhecida, sendo de pouca utilidade quando aplicada de forma incorreta. Neste caso, é muito comum o produtor, administrar quantidades de concentrado acima das necessidades da vaca, causando, com isto, desperdício de alimento e aumento do custo de produção. Observa-se, também, que a distribuição em quantidades que não atendem aos requerimentos da produção, trazem consequências para o animal. Afirma Islabão (1988) que o uso indiscriminado de concentrado na bovinocultura leiteira, além de ser antieconômico, pode reduzir o teor de gordura do leite. Portanto, a suplementação alimentar na produção de leite deve ser um meio para que o criador possa manter seus animais em um adequado nível nutricional (Languidey \& Araújo, 1983).

Assim, esse trabalho foi conduzido com os objetivos de estudar no período de estiagem o desempenho de vacas em lactação, mantidas em pasto diferido e suplementadas com palma forrageira, associada a diferentes fontes de proteína, e medir a disponibilidade e composição botânica da pastagem após período de diferimento.

\section{Material e Métodos}

O trabalho foi executado na Estação Experimental da Empresa Pernambucana de Pesquisa Agropecuária - IPA, Caruaru-PE, numa área de pastagem diferida sete meses antes do experimento (correspondendo ao período mais favorável de crescimento), com 14 ha, dividida em dois piquetes de mesmo tamanho, em que predominavam capins nativos e a gramínea exótica Brachiaria decumbens Stapf.

Segundo Encarnação (1980), este município fica localizado na microrregião do Agreste Setentrional Pernambucano. O clima é do tipo Dd'a' semi-árido megatérmico, ocorrendo duas estações distintas, uma chuvosa, chamada de inverno e a outra seca, conhecida como verão. A precipitação pluviométrica é irregular, apresentando média anual de $700 \mathrm{~mm}$, com $55 \%$ do total ocorrendo entre os meses de março e junho. O regime térmico é caracterizado por altas temperaturas, com valores máximos concentrados no período de outubro a janeiro. A temperatura média da região é de $29,6^{\circ} \mathrm{C}$.

Foram utilizadas 12 vacas mestiças 5/8 HolandoZebu, multíparas, com média de idade de sete anos, produção média de leite igual a $5,6 \mathrm{~kg} / \mathrm{dia} / \mathrm{vaca}$, paridas a aproximadamente 70 dias e peso vivo (PV) médio de $452 \mathrm{~kg}$.

O experimento começou em outubro de 1998 e terminou em fevereiro de 1999, com duração de 121 dias, sendo 21 destinados à adaptação das vacas às dietas experimentais.

No período da manhã, os animais ficaram no estábulo em baias individuais cobertas e piso de concreto. Neste local receberam água à vontade e alimento, conforme o tratamento experimental. À tarde, por volta das $13 \mathrm{~h}$, tiveram acesso aos piquetes de pastagem, com cochos contendo sais minerais, onde permaneceram até às 6 horas do dia seguinte.

A ordenha, com as crias ao pé, foi realizada manualmente, uma vez por dia, mais ou menos, às 6h30. Durante a execução do experimento, as crias mamavam, aproximadamente 10 minutos por dia e em seguida eram alojadas em estábulo separado, onde eram alimentadas no cocho, com farelo de milho, feno e sacharina de sorgo.

Os tratamentos experimentais foram compostos de diferentes fontes de proteína, associadas à palma (Opuntia ficus indica Mill) e pasto diferido, sendo as dietas experimentais calculadas segundo o NRC (1989) para uma produção de leite de $10 \mathrm{~kg} / \mathrm{dia} / \mathrm{vaca}$, com 3,5\% de gordura. Os componentes foram misturados de modo que houvesse equilíbrio entre as quantidades de energia e proteína fornecidas nos tratamentos, como pode ser observado na Tabela 1 . 
Tabela 1 - Composição das dietas experimentais in natura

Table 1 - Composition of the experimental diets, as fed basis

\begin{tabular}{|c|c|c|c|c|}
\hline \multirow[t]{2}{*}{$\begin{array}{l}\text { Tratamento } \\
\text { Treatment }\end{array}$} & \multicolumn{4}{|c|}{$\begin{array}{l}\text { Dieta } \\
\text { Diet }\end{array}$} \\
\hline & $\begin{array}{c}\text { Palma forrageira } \\
\text { Cactus forage }\end{array}$ & $\begin{array}{c}\text { Cama de frango } \\
\text { Broiler litter }\end{array}$ & $\begin{array}{c}\text { Farelo de soja } \\
\text { Soybean meal }\end{array}$ & $\begin{array}{l}\text { Uréia/s.amônio } \\
\text { Urea/amm. Sulphate }\end{array}$ \\
\hline & \multicolumn{4}{|c|}{$\begin{array}{c}\text { (kg/vaca/dia) } \\
(\mathrm{kg} / \text { cow/day })\end{array}$} \\
\hline 1 & 30 & 4 & - & - \\
\hline 2 & 45 & - & 1,4 & - \\
\hline 3 & 60 & - & - & 1,8 \\
\hline
\end{tabular}

A mistura uréia/sulfato de amônio na proporção de 9:1, foi fornecida adicionada a palma no período de adaptação, da seguinte forma: até o 50 dia, $60 \mathrm{~g}$; do $6^{\circ}$ ao $10^{\circ}$ dia, $120 \mathrm{~g}$; e a partir do $11^{\circ}$ dia, $180 \mathrm{~g}$. A cama de frango e a úreia também foram fornecidas adicionadas à palma.

Durante o período experimental, independentemente do tratamento, para cada $\mathrm{kg}$ de leite produzido acima dos $6 \mathrm{~kg} / \mathrm{dia} / \mathrm{vaca}$, foram fornecidos $400 \mathrm{~g}$ de uma mistura contendo $50 \%$ de farelo de trigo e $50 \%$ de farelo de soja.

Os farelos de soja e de trigo, a uréia e o sulfato de amônio foram adquiridos pelo IPA no comércio local. A cama de frango, tendo como material absorvente a palha de arroz, foi doada pela Granja Guararapes.

O peso dos animais foi determinado no início do período experimental, a cada 15 dias e no final do experimento, através de uma fita de pesagem para gado leiteiro. A produção média de leite in natura ( $\mathrm{kg} / \mathrm{dia} / \mathrm{vaca})$ foi determinada pela divisão entre a soma das produções diárias e o número de dias do período experimental. O valor do leite corrigido a $4 \%$ de gordura foi determinado conforme o NRC (1989).

Foram realizadas duas amostragens do leite sendo uma no início e outra no final do período experimental, para determinar o teor de gordura, a densidade e a acidez. As análises foram realizadas no Laboratório de Tecnologia Rural do Departamento de Tecnologia Rural da UFRPE, conforme metodologia de Almeida et al. (1993).

Amostras dos alimentos utilizados no arraçoamento dos animais foram coletadas com intervalos de 21 dias e enviadas ao Laboratório de Nutrição Animal do IPA, onde procederam-se as análises para determinar os teores de matéria seca (MS) e proteína bruta (PB), conforme metodologia de Silva (1990). Os teores de fibra em detergente neutro (FDN) e fibra em detergente ácido (FDA), foram realizados no Laboratório de Nutrição Animal do Departamento de Zootecnia da UFRPE, seguindo metodologia do mesmo autor.

$\mathrm{O}$ delineamento experimental utilizado foi o de blocos casualizados, sendo a produção média de leite o critério adotado para formação dos blocos. Os dados foram avaliados por meio de análise de variância e as médias foram comparadas pelo teste de Tukey, em nível de $5 \%$ de probabilidade.

Foram realizadas cinco avaliações de disponibilidade de forragem e composição botânica da pastagem, por piquete, a cada 28 dias. A primeira avaliação ocorreu antes das vacas terem acesso aos piquetes, as demais foram feitas durante o período experimental.

A estimativa da disponibilidade de forragem total foi obtida através do método do rendimento comparativo, utilizado por Haydock \& Shaw (1975), enquanto que os dados para estimar a composição botânica da pastagem, foram obtidos utilizando-se a metodologia do peso seco ordenado, descrita por Mannetje \& Haydock (1963), melhorada por Jones \& Hargreaves (1979). Para o processamento dos dados foi empregado o programa computacional BOTANAL, desenvolvido por Hargreaves \& Kerr (1978).

Em cada piquete foram traçados 18 transectos paralelos, no sentido transversal, ao longo dos quais foram realizadas as estimativas visuais em 10 pontos, distanciados um do outro $10 \mathrm{~m}$, aproximadamente, totalizando 180 estimativas visuais. Utilizou-se quadrados de ferro medindo 40 × $40 \mathrm{~cm}$ para as estimativas de disponibilidade e composição botânica.

No início da determinação da composição botânica, todas as espécies vegetais encontradas foram identificadas pelo nome vulgar regional. Depois, foram coletadas e enviadas ao herbário da Empresa Pernambucana de Pesquisa Agropecuária - IPA, onde tiveram a identificação botânica. 
As amostragens para determinar a composição botânica e a produção de matéria seca, foram realizadas simultaneamente nos quadrados-amostra e os dados apresentados representaram a média dos dois piquetes.

\section{Resultados e Discussão}

\section{Composição química dos alimentos}

A palma forrageira utilizada neste experimento, apresentou teor médio de MS igual a 115,6 g/kg, valor próximo ao obtido Santos et al. (2001), com 111,0 g/ $\mathrm{kg}$ (Tabela 2). Porém, foi inferior ao verificado por Mattos (2000), com 163,2 g/ kg. O teor de $36 \mathrm{~g} / \mathrm{kg}$ de PB foi inferior aos valores observados pelos mesmos autores, com 52,7 e $42,8 \mathrm{~g} / \mathrm{kg}$.

Os $256,5 \mathrm{~g} / \mathrm{kg}$ de FDN obtidas neste trabalho foram ligeiramente inferiores aos encontrados por Cunha (1996) e Mattos (2000), 267 g/kg. A quantidade de $172,7 \mathrm{~g} / \mathrm{kg}$ de FDA aquí observada, foi inferior à encontrada por Cunha (1996), com $215 \mathrm{~g} / \mathrm{kg}$, porém foi superior à identificada por Mattos (2000), com 142,9 g/kg. Convém esclarecer que, de maneira geral, os baixos teores de MS e PB da palma, implicam na ingestão de grandes quantidades desse alimento para que sejam atendidas as necessidades desses nutrientes. Além disso, é bom lembrar que animais alimentados com quantidades elevadas de palma, comumente, apresentam distúrbio digestivo (diarréia), o que, provavelmente, está associado à baixa quantidade de fibra dessa forrageira. Daí, a importância de complementá-la com volumosos ricos em fibra, a exemplo de silagens, fenos e capins secos.

O pasto diferido, com $893,4 \mathrm{~g} / \mathrm{kg}$ de MS foi superior ao valor encontrado por Fernandes et al. (1983) com $513 \mathrm{~g} / \mathrm{kg}$ aos 90 dias de diferimento do capim-de-raiz em São Caetano - PE e inferior ao de Moura (1987) que obteve $901 \mathrm{~g} / \mathrm{kg}$ para o diferimento do capim-buffel cv. Gayndah em Serra Talhada-PE. Houve superioridade para a quantidade de PB confirmada neste experimento que foi de $64,6 \mathrm{~g} / \mathrm{kg}$, quando comparada com os mesmos autores, que obtiveram 60 e $39 \mathrm{~g} / \mathrm{kg}$, respectivamente. Já os teores de FDN $(812,2 \mathrm{~g} / \mathrm{kg})$ e FDA $(508,1 \mathrm{~g} / \mathrm{kg})$ obtidas por Bonfim (2000) no município de Lavras - MG, aos sete meses de diferimento do capim-braquiária, foram superiores às encontradas no presente trabalho que foram $788 \mathrm{e}$ $443,7 \mathrm{~g} / \mathrm{kg}$, respectivamente. Torna-se oportuno esclarecer que a forragem na forma de feno em pé contribuiu para elevar os conteúdos de matéria seca e fibra em detergente neutro da dieta. Nesse sentido, Corsi (1990) afirmou que o estádio de maturidade das forrageiras é acompanhado pelo aumento da matéria seca, ocorrendo, com isso, diminuição na porção de carboidratos solúveis e aumento na fração de baixa digestibilidade da planta.

Tabela 2 - Composição química dos alimentos, Caruaru - PE Table 2 - Feed chemical composition, Caruaru - PE

\begin{tabular}{|c|c|c|c|c|}
\hline $\begin{array}{l}\text { Alimento } \\
\text { Feed }\end{array}$ & $\begin{array}{c}\mathrm{MS} \\
D M \\
(\mathrm{~g} / \mathrm{kg})\end{array}$ & $\begin{array}{l}\mathrm{PB} \\
C P\end{array}$ & $\begin{array}{c}\text { FDN } \\
N D F \\
(\mathrm{~g} / \mathrm{kg} \text { na } \mathrm{MS}) \\
(\mathrm{g} / \mathrm{kg} \text { in } D M) \\
\end{array}$ & $\begin{array}{l}\text { FDA } \\
A D F\end{array}$ \\
\hline $\begin{array}{l}\text { Palma forrageira } \\
\text { Cactus forage }\end{array}$ & 115,6 & 36,0 & 256,5 & 172,7 \\
\hline $\begin{array}{l}\text { Cama de frango } \\
\text { Broiler litter }\end{array}$ & 857,4 & 288,8 & 458,7 & 230,6 \\
\hline $\begin{array}{l}\text { Farelo de soja } \\
\text { Soybean meal }\end{array}$ & 892,5 & 488,3 & 174,2 & 132,8 \\
\hline $\begin{array}{l}\text { Farelo de trigo } \\
\text { Wheat meal }\end{array}$ & 909,3 & 167,0 & 362,8 & 105,3 \\
\hline $\begin{array}{l}\text { Uréia/s. amônio* } \\
\text { Urea/amm. sulphate }\end{array}$ & - & 2662,5 & - & - \\
\hline $\begin{array}{l}\text { Pasto diferido } \\
\text { Differed forage plant }\end{array}$ & 893,4 & 64,6 & 788,0 & 443,7 \\
\hline
\end{tabular}

\footnotetext{
Fonte: Laboratórios de Nutrição Animal do IPA e da UFRPE.

Source: Animal Nutrition Laboratory from IPA and UFRPE.

* Equivalente protéico.

*Protein equivalent.
} 
Consumo de matéria seca (MS), proteina bruta $(P B)$ e fibra em detergente neutro (FDN) dos alimentos fornecidos no cocho

A análise de variância revelou superioridade $(\mathrm{P}<0,05)$ no consumo médio de MS para o tratamento com farelo de soja, em relação aos tratamentos com cama de frango e uréia/sulfato de amônio (Tabela 3). De maneira geral, o consumo de MS foi inferior às exigências recomendadas pelo NRC (1989) para uma produção de $10 \mathrm{~kg}$ de leite/dia. Entretanto, para esses valores deve ser acrescida a quantidade de MS ingerida via pasto diferido. Por outro lado, vale ressaltar que as diferenças de MS, independentemente do tratamento, provavelmente não foram atendidas na sua totalidade pelo pasto diferido, em função da qualidade do pasto (Tabela 2).

\section{Produção de leite e variação de peso vivo}

As médias de produção de leite in natura e corrigido para $4 \%$ de gordura, no tratamento com farelo de soja, foram superiores $(\mathrm{P}<0,05)$ às médias de produção dos tratamentos com cama de frango e uréia/sulfato de amônio, que, por sua vez, não diferiram significativamente entre si $(\mathrm{P}>0,05)$ (Tabela 4).

Considerando que o leite consumido pelos bezerros deve ser somado aos resultados obtidos no presente experimento, com médias de 3,38; 5,33 e 3,33 kg de leite/vaca/dia, para os tratamentos com cama de frango, farelo de soja e uréia/sulfato de amônio, conclui-se que as mesmas ficaram bem próximas do resultado verificado por Dias et al. (1998), em Arcoverde - PE, com produção de até $7,50 \mathrm{~kg} / \mathrm{vaca} / \mathrm{dia}$, utilizando animais Girolando em pastagens de capimpangola, com seis meses de diferimento.

Os valores de produção de leite, encontrados neste trabalho, provavelmente, foram afetados pela qualidade do pasto, pelo baixo consumo de matéria seca e por alguma deficiência de nutrientes consumidos. Vale ressaltar que a cama de frango teve pouca aceitabilidade pelos animais.

Como pode ser observado na Tabela 4, no tratamento com farelo de soja, as vacas apresentaram ganho médio de peso igual a $0,077 \mathrm{~g} / \mathrm{dia}$, conferindo-lhe diferença estatística significativamente superior $(\mathrm{P}<0,05)$, quando comparado com os tratamentos com cama de frango $(-0,351 \mathrm{~g} / \mathrm{dia} / \mathrm{vaca})$ e uréia/sulfato de amônio $(-0,401 \mathrm{~g} /$ dia/vaca $)$, que não diferiram entre si $(\mathrm{P}>0,05)$.

Como o tratamento com farelo de soja foi superior aos demais, provavelmente o ganho de peso observado sugere que não houve déficit de energia no balanceamento dos nutrientes ingeridos, ocasionado pelo maior consumo de palma, que, segundo Santos et al. (1992), trata-se de um alimento com alto teor de carboidratos solúveis. A perda de peso ocorrida nas vacas dos tratamentos com cama de frango e uréia/sulfato de amônio pode ser explicada por alguma deficiência de nutrientes ingeridos. Gomide (1993) afirma que animais com ingestão deficiente de nutrientes mobilizam suas reservas orgânicas para atenderem aos seus requerimentos de mantença e produção. Análise físico-química do leite

Em todos os tratamentos (Tabela 5), os percentuais de gordura não diferiram significativamente entre si

Tabela 3 - Consumo (kg/vaca/dia) de matéria seca (MS), proteína bruta (PB) e fibra em detergente neutro (FDN) dos alimentos fornecidos, Caruaru - PE ${ }^{1}$

Table 3 - Intake (kg/cow/day) of dry matter (DM), crude protein (CP) and neutral detergent fiber (NDF) of supplied feed, Caruaru - PE

\begin{tabular}{|c|c|c|c|c|c|}
\hline \multirow[t]{2}{*}{$\begin{array}{l}\text { Consumo } \\
\text { Intake }\end{array}$} & \multicolumn{3}{|c|}{$\begin{array}{c}\text { Tratamento } \\
\text { Treatment }\end{array}$} & \multirow[b]{2}{*}{$\mathrm{CV}^{2} \%$} & \multirow[b]{2}{*}{$\begin{array}{r}\mathrm{DMS}^{3} \\
M S D\end{array}$} \\
\hline & $\begin{array}{c}\text { Cama de frango } \\
\text { Broiler litter }\end{array}$ & $\begin{array}{l}\text { Farelo de soja } \\
\text { Soybean meal }\end{array}$ & $\begin{array}{l}\text { Uréia/S.amônio } \\
\text { Urea/amm.sulphate }\end{array}$ & & \\
\hline $\begin{array}{l}\mathrm{kg} \text { de } \mathrm{MS} / \mathrm{vaca} / \mathrm{dia} \\
\mathrm{kg} \text { of } \mathrm{DM} / \mathrm{cow} / \text { day }\end{array}$ & $3,84^{b}$ & $5,79^{\mathrm{a}}$ & $3,22^{b}$ & 11,42 & 1,06 \\
\hline $\begin{array}{l}\mathrm{kg} \text { de } \mathrm{PB} / \mathrm{vaca} / \mathrm{dia} \\
\mathrm{kg} \text { of } C P / \text { cow/day }\end{array}$ & $0,34^{\mathrm{c}}$ & $0,79^{a}$ & $0,62^{\mathrm{b}}$ & 6,75 & 0,09 \\
\hline $\begin{array}{l}\mathrm{kg} \text { de FDN/vaca/dia } \\
\mathrm{kg} \text { of } N D F / \text { cow/day }\end{array}$ & $1,15^{\mathrm{a}}$ & $1,40^{\mathrm{a}}$ & $0,78^{\mathrm{b}}$ & 11,96 & 0,29 \\
\hline \multicolumn{6}{|c|}{$\begin{array}{l}1 \text { Não foi estimado o consumo do pasto diferido. } \\
{ }^{2} \text { Coeficiente de variação. } \\
{ }^{3} \text { Diferença mínima significativa. } \\
\text { Valores nas linhas, seguidos das mesmas letras, não diferem estatisticamente entre si }(P>0,05) \text {, de acordo com o teste de Tukey. } \\
{ }^{1} \text { It was not estimated the differed forage intake. }\end{array}$} \\
\hline
\end{tabular}

R. Bras. Zootec., v.31, n.3, p.1315-1324, 2002 (suplemento) 
Tabela 4 - Produção de leite in natura (PL), produção de leite corrigida para 4\% de gordura (PLC) e variação de peso vivo de vacas (VPV), Caruaru - PE

Table 4 - Fresh milk yield (FMY), 4\% fat adjusted milk yield (AMY) and live weight variation of cows (LWV), Caruaru - PE

\begin{tabular}{|c|c|c|c|c|c|}
\hline \multirow[t]{2}{*}{$\begin{array}{l}\text { Consumo } \\
\text { Intake }\end{array}$} & \multicolumn{3}{|c|}{$\begin{array}{c}\text { Tratamento } \\
\text { Treatment }\end{array}$} & \multirow[b]{2}{*}{$\mathrm{CV}^{2} \%$} & \multirow[b]{2}{*}{$\begin{array}{c}\mathrm{DMS}^{2} \\
M S D \\
\end{array}$} \\
\hline & $\begin{array}{c}\text { Cama de frango } \\
\text { Broiler litter }\end{array}$ & $\begin{array}{l}\text { Farelo de soja } \\
\text { Soybean meal }\end{array}$ & $\begin{array}{l}\text { Uréia/S.amônio } \\
\text { Urea/amm.sulphate }\end{array}$ & & \\
\hline $\begin{array}{l}\mathrm{PL}(\mathrm{kg} / \mathrm{vaca} / \mathrm{dia}) \\
F M Y(\mathrm{~kg} / \text { cow/day })\end{array}$ & $3,38^{\mathrm{b}}$ & $5,33^{\mathrm{a}}$ & $3,38^{\mathrm{b}}$ & 22,19 & 1,94 \\
\hline $\begin{array}{l}\mathrm{PLC}(\mathrm{kg} / \mathrm{vaca} / \mathrm{dia}) \\
A M Y(\mathrm{~kg} / \text { cow } / \text { day })\end{array}$ & $3,15^{\mathrm{b}}$ & $4,98^{\mathrm{a}}$ & $3,11^{\mathrm{b}}$ & 19,94 & 1,62 \\
\hline $\begin{array}{l}\mathrm{VPV}(\mathrm{g} / \mathrm{dia} / \mathrm{vaca}) \\
L W V(\text { g/day/cow })\end{array}$ & $-0,351^{b}$ & $0,077^{\mathrm{a}}$ & $-0,401^{b}$ & 73,13 & 0,36 \\
\hline
\end{tabular}

${ }^{1}$ Coeficiente de variação.

2 Diferença mínima significativa.

Valores nas linhas, seguidos das mesmas letras não diferem estatisticamente entre si $(P>0,05)$, de acordo com o teste de Tukey.

${ }^{1}$ Coefficient of variation.

${ }^{2}$ Minimal standard deviation.

Values at the same line followed by the same letter do not differ (P>.05) according to Tukey test.

$(\mathrm{P}>0,05)$. Neste trabalho, o teor de gordura do leite igual a 3,6\% (tratamento com cama de frango), $3,7 \%$ (tratamento com farelo de soja) e 3,4\% (tratamento com uréia/sulfato de amônio), possivelmente, não foi afetado pela qualidade da dieta, pois, conforme Wilkinson, citado por Figueiredo (1996), alimentos com percentuais de FDN entre 35 e $45 \%$ garantem teor normal de gordura no leite.

A densidade e a acidez do leite estão dentro da faixa permitida, conforme Almeida et al. (1993).

\section{Disponibilidade de forragem}

O longo período de diferimento, sete meses, proporcionou grande acúmulo de MS/ha. A disponibilidade total de forragem variou durante os períodos de amostragem, em função das condições climáticas e do pastejo, havendo um declínio progressivo da forragem disponível (Tabela 6).

Observa-se que na primeira avaliação, o capimbraquiária foi o componente de maior disponibilidade de forragem (794 kg/ha), seguido das participações expressivas do capim-milhã (704 kg/ha), capim-mimoso $(644 \mathrm{~kg} / \mathrm{ha})$ e capim-arroz $(294 \mathrm{~kg} / \mathrm{ha})$. No outro extremo, verifica-se como componentes de menor participação o capim-de-raiz ( $2 \mathrm{~kg} / \mathrm{ha})$, leguminosas (7 kg/ha) e Panicum ( $8 \mathrm{~kg} / \mathrm{ha}$ ). Vale ressaltar que o capim-milhã, o capim-mimoso e o capim-arroz são forrageiras anuais nativas e representam grande parte da forragem disponível para animais na região Agreste de PE. Também é importante esclarecer que, entre as gramíneas de maior participação no pasto, o capim-braquiária foi o único que mostrou uma sequência na redução de disponibilidade da primeira à última avaliação. Provavelmente, este fato esteja associado à maior aceitabilidade do mesmo pelos animais.

Verifica-se, a partir da segunda e terceira avaliações a ausência dos componentes capim-de-raiz, Panicum e leguminosas. A diminuição das leguminosas, provavelmente, está associada ao pastejo seletivo e às influências das condições climáticas sobre esses componentes.

Como pode ser observado na Tabela 6 , houve redução na disponibilidade de forragem, ao longo do período experimental, porém esta ficou sempre superior a $1000 \mathrm{~kg} \mathrm{MS} /$ ha, quantidade mínima para garantir a máxima ingestão de forragem pelos animais, conforme Minson (1981). Vale salientar que o nível mínimo recomendado pelo mesmo autor foi obtido em plantas temperadas, por isso, estima-se que deve ser superior para pastos tropicais, considerando a qualidade dos mesmos. Assim, deve-se observar que em pastagem de menor qualidade, mais forragem deve estar disponível para permitir uma seletividade máxima, pois conforme Gardner (1986), mesmo quando uma só espécie é utilizada, o animal seleciona uma parte da planta, antes das demais. Neste sentido, Reis et al. (1997) recomendaram uma disponibilidade mínima de $2000 \mathrm{~kg}$ de MS/ha, independentemente da qualidade, justificando que valores menores reduzem o consumo de forragem. Por outro lado, Mannetje \& Ebersohn (1980) sugerem que nos trópicos, onde as gramíneas acumulam grande quantidade de material morto durante a estação seca, a relação entre forragem disponível e consumo aplica-se apenas à fração verde do pasto. 
Tabela 5 - Teor de gordura, densidade e acidez no leite produzido por vacas Girolando, Caruaru - PE Table 5 - Fat content, density and acidity of milk from Gir/Holstein cows, Caruaru - PE

\begin{tabular}{|c|c|c|c|c|c|}
\hline \multirow[t]{2}{*}{$\begin{array}{l}\text { Consumo } \\
\text { Intake }\end{array}$} & \multicolumn{3}{|c|}{$\begin{array}{l}\text { Tratamento } \\
\text { Treatment }\end{array}$} & \multirow[b]{2}{*}{$\mathrm{CV}^{2} \%$} & \multirow[b]{2}{*}{$\begin{array}{c}\mathrm{DMS}^{2} \\
M S D\end{array}$} \\
\hline & $\begin{array}{c}\text { Cama de frango } \\
\text { Broiler litter }\end{array}$ & $\begin{array}{c}\text { Farelo de soja } \\
\text { Soybean meal }\end{array}$ & $\begin{array}{l}\text { Uréia/S.amônio } \\
\text { Urea/amm.sulphate }\end{array}$ & & \\
\hline $\begin{array}{l}\text { Gordura do leite }(\%) \\
\text { Milk fat content }(\%)\end{array}$ & $3,6^{\mathrm{a}}$ & $3,7^{\mathrm{a}}$ & $3,4^{\mathrm{a}}$ & 5,6 & 0,37 \\
\hline $\begin{array}{l}\text { Densidade }\left(\mathrm{g} / \mathrm{cm}^{3}\right) \\
\text { Milk density }\left(\mathrm{g} / \mathrm{cm}^{3}\right)\end{array}$ & 1031,9 & 1031,8 & 1031,8 & & \\
\hline $\begin{array}{l}\text { Acidez }\left({ }^{\circ} \text { Dornic }\right) \\
\text { Milk acidity }\left({ }^{\circ} \text { Dornic }\right)\end{array}$ & 16,0 & 16,0 & 16,0 & & \\
\hline
\end{tabular}

${ }^{1}$ Coeficiente de variação.

2 Diferença mínima significativa.

Valores nas linhas, seguidos das mesmas letras não diferem estatisticamente entre si $(P>0,05)$, de acordo com o teste de Tukey.

1 Coefficient of variation.

2 Minimal standard deviation.

Values at the same line followed by the same letter do not differ (P>.05), according to Tukey test.

Tabela 6 - Disponibilidade de forragem ( $\mathrm{kg} / \mathrm{ha})$, conforme os períodos de avaliação, Caruaru/PE Table 6 - Forage availability according to the evaluation periods; Caruaru/PE

\begin{tabular}{|c|c|c|c|c|c|}
\hline \multirow[b]{2}{*}{$\begin{array}{l}\text { Componente botânico } \\
\text { Botanic component }\end{array}$} & \multicolumn{5}{|c|}{$\begin{array}{l}\text { Avaliação } \\
\text { Evaluation }\end{array}$} \\
\hline & $1^{\mathrm{a}}$ & $2^{\mathrm{a}}$ & $\begin{array}{c}3^{\mathrm{a}} \\
(\mathrm{kg} / \mathrm{ha})\end{array}$ & $4^{\mathrm{a}}$ & $5^{\mathrm{a}}$ \\
\hline Capim-arroz & 294 & 413 & 387 & 354 & 279 \\
\hline Capim-braquiária & 794 & 508 & 438 & 340 & 254 \\
\hline Capim-milhã & 704 & 668 & 518 & 594 & 359 \\
\hline Capim-mimoso & 644 & 366 & 573 & 511 & 337 \\
\hline Capim-de-raíz & 2 & - & - & - & - \\
\hline Outras gramíneas & 131 & 29 & 57 & 45 & 15 \\
\hline \multicolumn{6}{|l|}{ Othersgrasses } \\
\hline Ervas e arbustos & 115 & 31 & 27 & 27 & 15 \\
\hline \multicolumn{6}{|l|}{ Herbs and shrubs } \\
\hline Leguminosas & 7 & 4 & - & - & - \\
\hline \multicolumn{6}{|l|}{ Legumes } \\
\hline Panicum & 8 & - & - & - & - \\
\hline Total & 2699 & 2019 & 2000 & 1871 & 1259 \\
\hline Total & & & & & \\
\hline
\end{tabular}

Os resultados de disponibilidade de forragem, observados na primeira avaliação no presente trabalho (2699 $\mathrm{kg}$ de MS/ha) foram superiores aos encontrados por Fernandes et al. (1983), em São Caetano - PE, com $1488 \mathrm{~kg}$ de MS/ha aos 3 meses de diferimento do capim-de-raiz. Também foram maiores que os de Moura (1987), em Serra Talhada - PE, com produção média de 1596,7 kg de MS/ha durante seis meses de diferimento no capim-Buffel.

Por outro lado, vale resaltar a qualidade do pasto disponível, que após o diferimento, apresentou altos valores de fibra em detergente neutro (Tabela 2), o que pode ter limitado o consumo animal. Assim, é necessário estudar diferentes períodos de diferimento, objetivando identificar qual é o período que melhor associa a disponibilidade à qualidade do pasto, como também à composição botânica da pastagem.

\section{Composição botânica da pastagem}

Foram identificadas 18 famílias, 32 gêneros e 36 espécies (Tabela 7). A área experimental era formada predominantemente pelas gramíneas, no entanto observou-se a presença de componentes arbóreos/ arbustivos, típicos de área de caatinga, tais como: aroeira, baraúna, umbuzeiro, marmeleiro, canafístula, 
jurema preta, angico e juazeiro, entre outros. A presença de um grande número de espécies na pastagem de braquiária evidencia que apesar de grande agressividade, essa espécie nas condições de Caruaru$\mathrm{PE}$ teve alguma limitaçào de água.

$\mathrm{O}$ estrato herbáceo da área estudada era formado, principalmente, pela gramínea introduzida (Brachiaria decumbens Stapf) e capins nativos que constituíram, provavelmente, grande parte do material selecionado pelos animais.

Como pode ser observado na Tabela 8 , na primeira avaliação, as gramíneas (capins: arroz, braquiária, milhã, mimoso, raiz, Panicum e outras gramíneas) apresentaram maior participação na composição bo- tânica da pastagem, totalizando 95,48\%. O componente ervas e arbustos contribuiu com $4,26 \%$ e as leguminosas participaram apenas com $0,26 \%$. O capim-braquiária foi o componente de maior participação $(29,42$ \%) na composição botânica da pastagem, seguido das participações expressivas do capimmilhã $(26,08 \%)$, capim-mimoso $(23,86 \%)$ e capimarroz $(10,89 \%)$. Por outro lado, observa-se que as leguminosas tiveram baixo percentual de participação $(0,26 \%)$, provavelmente, comprometendo a qualidade da forragem disponível para o pastejo dos animais, em função da contribuição deste componente, em termos de valor nutritivo, quando comparado com gramíneas tropicais.

Tabela 7 - Espécies encontradas na área experimental, Caruaru - PE

Table 7 - Species that were found at the experimental area, Caruaru - PE

\begin{tabular}{|c|c|c|}
\hline $\begin{array}{l}\text { Família } \\
\text { Family }\end{array}$ & $\begin{array}{c}\text { Gênero/espécie } \\
\text { Genus/specie }\end{array}$ & $\begin{array}{l}\text { Nome vulgar } \\
\text { Common name }\end{array}$ \\
\hline Acanthaceae & Ruellia sp. & Cipó \\
\hline Anacardiaceae & Astronium urundeuva Engl. & Aroeira \\
\hline Anacardiaceae & Schinopsis Brasiliensis Engl. & Barauna \\
\hline Anacardiaceae & Spondias tuberosa Arr. Cam. & Umbuzeiro \\
\hline Asteraceae & Melanthera latifolia (Gardn) Cabrera & Carrapicho \\
\hline Burseraceae & Bureera leptophloeae Mart. & Imburana \\
\hline Cactaceae & Cereus jamacaru DC. & Mandacaru \\
\hline Cactaceae & Piloscereus piauhyensis (Guerke) B. et R. & Facheiro \\
\hline Caesalpinioideae & Cassiaexcelsa Scharad & Canafístula \\
\hline Commelinaceae & Commelina sp. & Olho de Santa Luzia \\
\hline Cyperaceae & Cyperus aff. Uncinulatus Scharad & Capim navalha \\
\hline Euphorbiaceae & Croton sonderianus Muell Arg. & Marmeleiro \\
\hline Euphorbiaceae & Jatropha mollissima Pohl & Pinhão \\
\hline Euphorbiaceae & Tragia volubilis L. & Urtiga \\
\hline Gramineae & Anthephora hermaphrodita L Ktze & Capim-arroz \\
\hline Gramineae & Brachiaria decumbens Stapf & Braquiária de pêlo \\
\hline Gramineae & Brachiaria plantaginea (Link) Hitch & Capim-milhã \\
\hline Gramineae & Cenchrus echinatus L. & Espinho-de-bola \\
\hline Gramineae & Chloris orthonoton Doell & Capim-de-raiz \\
\hline Gramineae & Dactyloctenium aegytium (L.) Beauv & Capim-pé-de-galinha \\
\hline Gramineae & Digitaria sp. & Capim-estrela \\
\hline Gramineae & Digitaria insularis Mez ex Ekman & Capim-de-flecha \\
\hline Gramineae & Gymnopogon rupestris Ridley & Capim-mimoso \\
\hline Gramineae & Panicum maximum & Capim-colonião \\
\hline Gramineae & Panicum maximum Jacq & Capim-sempre-verde \\
\hline Leguminoseae & Erythrina velutina Wild & Mulungu \\
\hline Leguminoseae & Mimosa sp. ${ }^{1}$ & Jurema preta \\
\hline Leguminoseae & Mimosa sp. ${ }^{2}$ & Maliça \\
\hline Leguminoseae & Stylosanthes capitata Vog & Alfafa do Nordeste \\
\hline Leguminoseae & Piptadenia sp. & Angico \\
\hline Nyctaginaceae & Boerhavia coccinea Mill & Pega-pinto \\
\hline Passifloraceae & Passiflora foetida $\mathrm{L}$. & Maracujá de estalo \\
\hline Rhamnaceae & Zizyphus joazeiro Mart. & Juazeiro \\
\hline Scrophulariaceae & Scoparia dulcis L. & Vassourinha \\
\hline Solanaceae & Solanum aculeatissimum Jacq. & Gogóia \\
\hline Teraceae & Blainvillea rhomboidea Cass. & Avanço \\
\hline Vitaceae & Cissus simsiana $\mathrm{R}$. et $\mathrm{S}$. & Parreira \\
\hline
\end{tabular}


Tabela 8 - Composição botânica da pastagem, Caruaru - PE

Table 8 - Botanical composition of the pasture, Caruaru - PE

\begin{tabular}{|c|c|c|c|c|c|}
\hline \multirow[b]{2}{*}{$\begin{array}{l}\text { Componente botânico } \\
\text { Botanic component }\end{array}$} & \multicolumn{5}{|c|}{$\begin{array}{l}\text { Avaliação } \\
\text { Evaluation }\end{array}$} \\
\hline & $1^{\mathrm{a}}$ & $2^{\mathrm{a}}$ & $\begin{array}{l}3^{\mathrm{a}} \\
(\%)\end{array}$ & $4^{\mathrm{a}}$ & $5^{\mathrm{a}}$ \\
\hline$\overline{\text { Capim-arroz }}$ & 10,89 & 20,46 & 19,35 & 18,92 & 22,16 \\
\hline Capim-braquiária & 29,42 & 25,16 & 21,90 & 18,17 & 20,17 \\
\hline Capim-milhã & 26,08 & 33,08 & 25,90 & 31,75 & 28,52 \\
\hline Capim-mimoso & 23,86 & 18,13 & 28,65 & 27,31 & 26,77 \\
\hline Capim-de-raiz & 0,07 & - & - & - & - \\
\hline Outras gramíneas & 4,86 & 1,44 & 2,85 & 2,41 & 1,19 \\
\hline $\begin{array}{l}\text { Ervas e arbustos } \\
\text { Herbs and shrubs }\end{array}$ & 4,26 & 1,53 & 1,35 & 1,44 & 1,19 \\
\hline $\begin{array}{l}\text { Leguminosas } \\
\text { Legumes }\end{array}$ & 0,26 & 0,20 & - & - & - \\
\hline Panicum & 0,30 & - & - & - & - \\
\hline
\end{tabular}

\section{Conclusões}

A suplementação com farelo de soja promoveu produção de leite superior às suplementações com cama de frango e úreia.

$\mathrm{O}$ pasto diferido associado à palma forrageira $\mathrm{e}$ farelo de soja é uma alternativa de alimentação para animais mestiços no Agreste de Pernambuco.

$\mathrm{O}$ pasto diferido apresentou variação quanto à disponibilidade de forragem e composição botânica ao longo do período de utilização.

\section{Literatura Citada}

ALMEIDA, A.A.P.; PEREIRA, D.B.C.; ARCURI, E.F. et al. Controle de qualidade de leite pasteurizado. Instituto de Laticínios Cândido Tostes, 1993. 83p.

ALVES, A.A. Fontes alternativas de cama de frangos para alimentação de ruminantes. Fortaleza: Universidade Federal do Ceará, 1991. 88p. Dissertação (Mestrado em Zootecnia) - Universidade Federal do Ceará, 1991.

BONFIM, M.A.D. Níveis de Concentrado na Terminação de Novilhos Holandês x Zebu Suplementados a Pasto na Estação Seca. Lavras: Universidade Federal de Lavras, 2000. 64p. Dissertação (Mestrado em Zootecnia) - Universidade Federal de Lavras, 2000.

CAMPLING, R.C.; MURDOCH, J.C. The effect of concentrates on the voluntary intake of roughage by cows. Journal Dairy Research, v.33, n.11, p.1-11,1966.

CARVAlHO FILHO, O.M.; LANGUIDEY, P.H. Palma forrageira semi-desidratada associada a diferentes fontes protéicas para vacas em lactação. Petrolina - PE: EMBRAPA - CPATSA, 1997. 4p. (EMBRAPA. Comunicado Técnico, 72).

CORSI, M. Produção e qualidade de forragens tropicais. In: Pastagens. Campinas: Sociedade Brasileira de Zootecnia, 1990. p.69-85.

R. Bras. Zootec., v.31, n.3, p.1315-1324, 2002 (suplemento)
CUNHA, M.G.G. Efeito da adição de fibra em dietas à base de palma forrageira (Opuntia ficus indica Mill) sobre os parâmetros da fermentação ruminal e da digestibilidade em ovinos. Recife: Universidade Federal Rural de Pernambuco, 1996. 70p. Dissertação (Mestrado em Zootecnia) Universidade Federal Rural de Pernambuco, 1996.

DIAS, F.M.; SANTOS, D.C.; LIRA, M.A. et al. Estudo comparativo de diferentes áreas de diferimento em pastagens de capim pangola (Digitaria decumbens Stent) para produção de leite. In: CONGRESSO NORDESTINO DE PRODUÇÃO ANIMAL, 1., 1998, Fortaleza. Anais... Fortaleza: Sociedade Nordestina de Produção Animal, 1998. p.97.

ENCARNAÇÃO, C.R.F.. Observações meteorológicas e tipos climáticos das Unidades e Campos Experimentais da Empresa IPA. Recife: IPA, 1980. 110p.

FERNANDES, A.P.M.; FARIAS, I.; LIRA, M.A. et al. Efeito de diferentes períodos de diferimento sobre o pasto de capim de raiz (Chloris orthonoton, Doell.). In: I CONGRESSO BRASILEIRO DE FORRAGEIRAS E PASTAGENS NATIVAS. Anais... Empresa Pernambucana de Pesquisa Agropecuária - IPA e Empresa Brasileira de Pesquisa Agropecuária - EMBRAPA. Olinda, 1983.

FIGUEIREDO, M.P. Nutrição de bovinos leiteiros e doenças metabólicas. Bahia Agrícola, v.1, n.2, p.51-61, 1996.

FRANÇA, J.G.E.; ALVES, A.; LIRA, A. et al. Sistema Agroindustrial do leite em Pernambuco. Documento preliminar, Recife: SEBRAE - PE, 1999. 106p.

GARDNER, A.L. Técnicas de pesquisa em pastagens e aplicabilidade de resultados em sistemas de produção. Brasília, IICA/EMBRAPA - CNPGL, 1986. 197p.

GOMIDE, J.A. Produção de leite em regime de pasto. Revista da Sociedade Brasileira de Zootecnia, v.22, n.4, p.591-613, 1993.

HARGREAVES, J.N.G.; KERR, J.D. BOTANAL. A comprehensive sampling and computing procedure for estimating pasture yield and composition.II. Computacional package. St. Lucia: CSIRO - Division of Crops and Pastures, 1978. 88 p. (CSIRO Tropical Agronomy Technical Memorandum 9).

HAYDOCK, K.P.; SHAW, N.H. The comparative yield method 
for estimating dry matter yield of pasture. Australian Journal of Experimental Agriculture and Animal Husband, v.15, n.76, p.663-670, 1975.

ISLABÃO, N.Manual de cálculo de rações para os animais domésticos. 5.ed. Porto Alegre: SAGRA, 1988. 184p.

JONES, R.M.; HARGREAVES, J.N.G. Improvements to the dry-weight-rank method for measuring botanical composition. Grass and Forage Science, v.34, n.2, p.181-189, 1979.

KESLER, E.M.; SPAHR, S.L. Symposium: effect of various levels of grain feeding: Physiological effects of high level concentrate feeding. Journal of Dairy Science, v.47, n.10, p.1122-1128, 1964.

LANGUIDEY, P.H.; ARAÚJO, E.C. Suplementação protéica e/ou energética para vacas em lactação, na região úmida do Estado de Sergipe. Aracaju: EMBRAPA - UEPAE, 1983. 4 p. (Comunicado Técnico, 10).

't MANNETJE, L.; EBERSOHN, J.B. Relations between sward characteristics and animal production.Tropical Grassland, v.14, p.273-280, 1980

t'MANNETJE, L.; HAYDOCK, K.P. The dry-weight-rank for the botanical analysis of pasture. Journal Bristh Grassland Science, v.18, p.268-275, 1963.

MARASCHIN, G.E. Sistema de pastejo, 1. In: SIMPÓSIO SOBRE MANEJO DE PASTAGEM, 8., 1986, Piracicaba. Anais... Piracicaba: Escola Superior de Agricultura Luiz de Queiroz, 1986. p.261-290.

MATTOS, L.M.E. Associação da palma forrageira (Opuntia ficus indica Mill) com diferentes fontes de fibra na alimentação de vacas mestiças em lactação. Recife: Universidade Federal Rural de Pernambuco, 2000. 51p. Dissertação (Mestrado em Zootecnia) - Universidade Federal Rural de Pernambuco, 2000.

MINSON, D.J. Forage quality: assessing the plant-animal complex. In: INTERNATIONAL GRASSLAND CONGRESS, 15., 1981, Kentucky. Proceedings... Kentucky: 1981. p.23-29.

MOURA, J.W.S. Disponibilidade e qualidade de pastos nativos e de capim-Buffel (Cenchrus ciliaris L.) diferido no semiárido de Pernambuco. Recife: Universidade Federal Rural de Pernambuco, 1987. 159 p. Dissertação (Mestrado em Zootecnia) - Universidade Federal Rural de Pernambuco, 1987.

NEIVA, J.N.M.; SANTOS, M.V.F. Manejo de pastagens cultivadas em regiões semi-áridas. In: CONGRESSO NORDESTINO DE PRODUÇÃO ANIMAL, 1., Fortaleza, 1998. Anais... Fortaleza: Sociedade Nordestina de Produção Animal, 1998. v.1. p.35-45.
NATIONAL RESEARCH COUNCIL - NRC. Nutrient requirements of the dairy cattle. 6.ed. Washington, D.C.: 1989. $157 \mathrm{p}$.

OLIVEIRA, M.D.S.; VIEIRA, P.S.; SAMPAIO, A.A.M. Efeito do tempo de estocagem sobre a composição bromatológica da cama de frangos. Revista da Sociedade Brasileira de Zootecnia, v.17, n.2, p.115-119, 1988.

PIMENTEL, J.C.M. Fatores críticos ao Desenvolvimento do Sistema Agroindustrial do Leite no Nordeste, 1. In: CONGRESSO NORDESTINO DE PRODUÇÃO ANIMAL. Fortaleza-CE, 1998. Anais... Fortaleza: Sociedade Nordestina de Produção Animal, 1998. v.3. p.43-57.

REIS, R.A.; RODRIGUES, L.R.A.; PEREIRA, J.R.A. A suplementação como estratégia de manejo da pastagem. In: SIMPÓSIO SOBRE MANEJO DA PASTAGEM, 13., 1997, Piracicaba. Anais... Piracicaba: Fundação de Estudos Agrários Luiz de Queiroz, 1997. p.123-150.

SANTOS, M.V.F.; LIRA, M.A.; FARIAS, I. Efeito do período de armazenamento pós-colheita sobre o teor de matéria seca e composição das palmas forrageiras. Pesquisa Agropecuária Brasileira, v.27, n.6, p.777-783, 1992.

SANTOS, M.V.F.; FARIAS, I.; LIRA, M.A. et al. Colheita da palma forrageira (Opuntia ficus indica Mill) cv.Gigante sobre o desenvolvimento de Vacas em lactação. Revista Brasileira de Zootecnia, v.27, n.1, p.33-39, 1998.

SANTOS, D.C.; SANTOS, M.V.F.; FARIAS, I. et al. Desempenho produtivo de vacas $5 / 8$ holando/zebu alimentadas com diferentes cultivares de palma forrageira (Opuntia e Nopalea). Revista Brasileira de Zootecnia, v.30, n.1, p.13-18, 2001.

SILVA, D.J. Análise de alimentos: métodos químicos e biológicos. 2.ed. Viçosa, MG: Universidade Federal de Viçosa, 1990. 165 p. 